\title{
In search of parsimony: reliability and validity of the Functional Performance Inventory-Short Form
}

This article was published in the following Dove Press journal:

International Journal of COPD

24 November 2010

Number of times this article has been viewed

\author{
Nancy Kline Leidy' \\ Ann Knebel ${ }^{2}$ \\ 'Center for Health Outcomes \\ Research, United BioSource \\ Corporation, Bethesda, MD, USA; \\ ${ }^{2}$ Office of the Assistant Secretary \\ for Preparedness and Response, US \\ Department of Health and Human \\ Services, Washington, DC, USA
}

Purpose: The 65-item Functional Performance Inventory (FPI), developed to quantify functional performance in patients with chronic obstructive pulmonary disease (COPD), has been shown to be reliable and valid. The purpose of this study was to create a shorter version of the FPI while preserving the integrity and psychometric properties of the original.

Patients and methods: Secondary analyses were performed on qualitative and quantitative data used to develop and validate the FPI long form. Seventeen men and women with COPD participated in the qualitative work, while 154 took part in the mail survey; 54 completed 2 -week reproducibility assessment, and 40 relatives contributed validation data. Following a systematic process of item reduction, performance properties of the 32-item short form (FPI-SF) were examined.

Results: The FPI-SF was internally consistent (total scale $\alpha=0.93$; subscales: $0.76-0.89$ ) and reproducible ( $r=0.88$; subscales: $0.69-0.86)$. Validity was maintained, with significant $(P<0.001)$ correlations between the FPI-SF and the Functional Status Questionnaire (activities of daily living, $r=0.71$; instrumental activities of daily living, $r=0.73$ ), Duke Activity Status Index ( $r=0.65)$, Bronchitis-Emphysema Symptom Checklist $(r=-0.61)$, Basic Need Satisfaction Inventory ( $r=0.61)$ and Cantril's Ladder of Life Satisfaction $(r=0.63)$, and Katz Adjustment Scale for Relatives (socially expected activities, $r=0.51$; free-time activities, $r=-0.49$, $P<0.01$ ). The FPI-SF differentiated patients with an $\mathrm{FEV}_{1} \%$ predicted greater than and less than $50 \%(t=4.26, P<0.001)$, and those with severe and moderate levels of perceived severity and activity limitation $(t=9.91, P<0.001)$.

Conclusion: Results suggest the FPI-SF is a viable alternative to the FPI for situations in which a shorter instrument is desired. Further assessment of the instrument's performance properties in new samples of patients with COPD is warranted.

Keywords: functional status, health outcomes, activities of daily living, COPD, patient-reported outcomes, chronic pulmonary disease, health-related quality of life

\section{Introduction}

Evaluating functional status reliably, validly, and simply is an ongoing challenge in pulmonary research. One dimension of functional status is functional performance, defined as the physical, psychological, social, occupational, and spiritual activities that people actually $d o$ in the normal course of their lives as they attempt to meet basic needs, fulfill usual roles, and maintain their health and well-being. ${ }^{1,2}$ These activities are chosen by the individual based on personal preference, subject to the limits imposed by capacity, and generally require less than functional capacity to accomplish. ${ }^{1,2}$ Functional performance includes what has been frequently referred to as activities of daily living
Correspondence: Nancy Kline Leidy Center for Health Outcomes Research, United BioSource Corporation,

7101 Wisconsin Avenue, Suite 600, Bethesda, MD 208I4, USA

Tel + I 30I 6547272

Fax + I 30I 6549864

Email nancy.leidy@unitedbiosource.com 
(ADL), instrumental activities of daily living (IADL), and/or self-care activities, as well as corporeal activities in the recreational, social, and spiritual domains.

The Functional Performance Inventory (FPI) is a 65-item self-administered questionnaire designed to evaluate functional performance in patients with chronic obstructive pulmonary disease (COPD). ${ }^{3}$ Although the instrument has exhibited evidence of reliability and validity, the length can be prohibitive, particularly in studies involving multiple patient-reported outcomes.

The purpose of this study was to reduce the length of the FPI, creating a short form (FPI-SF) that preserved the conceptual integrity and psychometric properties of the original instrument. This article provides a background on the development and validation of the long form and describes the process used to eliminate items and evaluate the reliability and validity of the FPI-SF relative to the longer version using data from the original validation study.

\section{Background: the FPI Content validity}

An in-depth literature review and qualitative interviews with men and women with moderate to severe COPD informed the overall structure of the FPI, including the six domains of assessment, content of the items within each domain, response options, instructions for completing the instrument, and scoring. ${ }^{4}$

The draft FPI was evaluated by 24 specialists in COPD from across the United States, with each expert using their experience to rate the relevance of each item on a 4-point scale, from not at all (1) to very relevant (4). Based on this feedback, items were revised, reorganized, and clarified. The revised tool was submitted to seven new experts for review. The content validity index (CVI; percentage of items rated
3 or 4 (relevant or very relevant) ( $^{5,6}$ by at least six of the seven experts) for the FPI was $86 \%$. Of the seven experts, five rated all of the items relevant or very relevant (3 or 4 ).

The instrument was pretested with five patients with COPD using cognitive interviewing techniques. Specifically, participants were interviewed about the clarity and ease of understanding the instructions, comprehensiveness of the questions, and content of the items and response options. Based on patient feedback, several adjustments were made to the instructions; no changes in item content or response options were required. ${ }^{3}$

Since the development of the FPI, several studies have been published providing further support for the content validity of the instrument. These studies include qualitative studies of patients with moderate to severe COPD, ${ }^{7}$ elderly patients with limited ability to perform daily activities, ${ }^{8}$ and expert review of its suitability for use in Taiwan ${ }^{9}$ and Turkey. ${ }^{10}$ A literature review of functional performance measures used in clinical studies from 1995 to 2005 described content across nine instruments and found that seven different domains were covered to varying degrees (personal care, mobility, household tasks, recreation, social activities, religious/spiritual activities, and sexual activity), with the FPI offering the most comprehensive assessment. ${ }^{11}$

\section{FPI structure}

For ease of administration, the FPI is organized according to the six domains of functional performance identified during the qualitative interviews: body care, household maintenance, physical exercise, recreation, spiritual activities, and social activities. Sample items for each subscale are provided in Table 1. For each activity, response options range from 1 (the activity can be performed easily, with no difficulty at all) to 4 (the activity is no longer performed for

Table I Sample items from the FPI and FPI-SF

\begin{tabular}{|c|c|c|c|}
\hline \multirow[t]{2}{*}{ Dimension } & \multicolumn{2}{|c|}{ No. of items } & \multirow[t]{2}{*}{ Sample content } \\
\hline & FPI & FPI-SF & \\
\hline \multirow[t]{2}{*}{ Body care } & 9 & 5 & Showering or bathing \\
\hline & & & Caring for your feet \\
\hline \multirow[t]{2}{*}{ Household maintenance } & 21 & 8 & Carrying groceries \\
\hline & & & Moving furniture, changing sheets, or washing windows \\
\hline \multirow[t]{2}{*}{ Physical exercise } & 7 & 5 & Walking up and down a flight of stairs \\
\hline & & & Long, fast walks (>20 min) \\
\hline \multirow[t]{2}{*}{ Recreation } & II & 5 & Indoor activities such as shopping or museums \\
\hline & & & Sitting outside \\
\hline \multirow[t]{2}{*}{ Spiritual activities } & 5 & 4 & Attending religious services \\
\hline & & & Visits from spiritual friends or teachers \\
\hline \multirow[t]{2}{*}{ Social activities } & 12 & 5 & Helping in the care of children \\
\hline & & & Distant or overnight travel to visit others \\
\hline
\end{tabular}


health reasons). A 'not applicable' option is also available for patients who choose not to perform a given activity for reasons other than health. The instructions ask subjects to circle the number that best describes how difficult it is for them to perform each activity.

To score the instrument, subjects receive no points for activities they do not perform, whether for health or other reasons ( 0 points). The remaining three options are reversed, so a subject who performs an activity with no difficulty receives 3 points, some difficulty $=2$ points, and much difficulty $=1$ point $(1=3,2=2$, and $3=1)$. Total and subscale scores are expressed as mean values, with an $80 \%$ completion rate required for calculation. Scores range from 0 to 3 , with higher scores indicating higher levels of function.

\section{Reliability and validity}

Several validation studies were conducted to assess the psychometric properties of the FPI in patients with COPD. ${ }^{3,12,13}$ Internal consistency reliability levels for the total score were high in all studies $(\alpha=0.89-0.98)$. More recently, Reishtein ${ }^{14}$ and Kapella et al ${ }^{15}$ reported reliability levels of $0.73(\mathrm{n}=100)$ and $0.92(\mathrm{n}=130)$, respectively. The 2 -week reproducibility (intraclass correlation coefficient (ICC)) for the total scale is 0.87 , with subscale score ICCs ranging from 0.66 (physical exercise) to 0.89 (household maintenance). ${ }^{3}$

In the original validation work, validity of the FPI was correlated $(r)$ with the following criterion variables (unless otherwise specified, coefficients correspond to the two validation studies, respectively $\left.{ }^{3,13}\right)$ : Functional Status Questionnaire (FSQ) ADL (0.68; 0.61) and IADL Scales (0.68; 0.70); the Duke Activities Status Index (DASI) (0.61; 0.43); the Katz Adjustment Scale for Relatives (KAS-R) Scales for Socially Expected (0.53) and Free-Time Activities (-0.49); pulmonary function forced expiratory volume in one second ( $\mathrm{FEV}_{1} \%$ predicted) $(0.34 ; 0.55) ; 12$-minute walk distance (12-MWD) (0.52); ${ }^{13}$ the NIH Activity Record Diary Dyspnea $(-0.59)$, Fatigue $(-0.62)$, and Difficulty $(-0.71)$ Scales $;^{13}$ Bronchitis Emphysema Symptom Checklist (BESC) (-0.59); the Basic Need Satisfaction Inventory (BNSI) (0.61); and Cantril's Self-anchoring Ladder of Life Satisfaction (0.63). ${ }^{3}$ The FPI was also validated against the Sickness Impact Profile (-0.59), American Thoracic Society and the Division of Lung Disease Breathlessness Scale (0.62), the Medical Outcomes Study Short Form 36, Physical Functioning Scale (0.69), and the Physical Activity Scale for the Elderly $(0.62) .^{12}$

The study of Kapella et a ${ }^{15}$ regarding the consequences of fatigue in 139 patients with COPD found significant correlations between the FPI and several variables, providing additional support for the construct validity of the tool. Correlations with the FPI were as follows: $\mathrm{FEV}_{1} \%$ predicted (0.30), Chronic Respiratory Disease Questionnaire (0.48), Numerical Rating Scale of Dyspnea (-0.59), POMS Fatigue $(-0.46)$, Numerical Rating Scale of Fatigue $(-0.52)$, Anxious Mood (-0.43), Depressed Mood (-0.31), and Sleep Quality $(-0.32)$ ( $n=130)$. Reishtein's study of 100 moderate to severe COPD patients $\left(\mathrm{FEV}_{1} \% \leq 60 \%\right)^{14}$ reported significant moderate negative relationships between the FPI and dyspnea $(r=-0.51, P \leq 0.01)$ and fatigue $(r=-0.27, P<0.01)$.

\section{Material and methods Item selection}

The aim of this study was to reduce the length of the FPI by $50 \%$, to fewer than 34 items, while maintaining the subscale structure, reliability, and validity of the instrument. Items were selected for content validity based on the qualitative data and contribution to subscale reliability. The 65 items comprising the FPI were first reviewed for their content validity, with items prioritized for retention based on patient reports of their importance to daily functioning and clinician ratings of relevance to clinical assessment. Redundant or overlapping items were also identified for possible elimination. Item-to-subscale correlations and the contribution of items to subscale internal consistency reliability were then examined using data from the original FPI validation study (sample and data are described below). Redundant items that did not contribute to reliability were excluded.

Thirty-two items were selected for inclusion in the FPI-SF: body care (five items), household maintenance (eight items), physical exercise (five items), recreation (five items), spiritual activities (four items), and social activities (five items). Sample items are provided in Table 1. Consistent with the longer version, subscale and total scores for the FPI-SF are computed by taking the mean across items, with an $80 \%$ completion rate required for calculation. Higher scores indicate better functioning.

\section{Expert review}

Expert ratings data from the development process were used to summarize the CVI for the FPI-SF. Because expert ratings were also used for item reduction, it was expected that this value would be very high.

\section{Reliability and validity testing}

To examine the performance of the FPI-SF relative to the long form, data from the original validation study were 
used to test the reliability and validity. ${ }^{3}$ Because items were eliminated based, in part, on their contribution to reliability, internal consistency levels were expected to be equivalent to or greater than the original instrument. The FPI and FPI-SF subscale and total scores were correlated to provide insight into the 'upper bound' of the relationship between the two versions.

\section{Measures}

\section{Concurrent validity}

Concurrent validity was evaluated by correlating the FPI-SF with three measures of day-to-day activity: the FSQ, the DASI, and the KAS-R. These instruments are consistent with the construct of performance as defined in the theoretical framework but were not developed specifically for the COPD population and are less targeted in their assessment. Thus, moderate correlations between these measures and the FPI-SF were anticipated.

\section{FSQ}

Two of the six subscales of the FSQ were used in the analyses: basic ADL (three items) and IADL (six items). ${ }^{16,17}$ The FSQ has been tested for reliability and validity in various clinical populations and has been used as an indicator of functional status in a number of studies. ${ }^{16,18-25}$ Reliability estimates (Cronbach's $\alpha$ ) for the FSQ-ADL and IADL current sample were 0.81 and 0.91 , respectively.

\section{DASI}

The 12-item DASI is designed to tap physical fitness and cardiac functional capacity indirectly by asking subjects to evaluate their ability to perform various activities. ${ }^{26}$ Each activity is weighted according to its known metabolic cost in metabolic equivalent units. The DASI has been correlated with peak oxygen uptake and with the Canadian Cardiovascular Society Classification. The internal consistency reliability for the DASI in this study was 0.85 .

\section{KAS-R}

The KAS-R assesses patient adjustment and functioning in the areas of social role and free-time activities, as perceived by a relative or confidant. The KAS-R has been shown to approximate clinical judgment and has discriminated between well-adjusted patients and poorly adjusted patients. ${ }^{27,28}$ It has also been used successfully in studies of patients with COPD. ${ }^{29-31}$ Two subscales were used to validate the FPISF: performance of socially expected activities (16 items, $\alpha=0.88$ ) and free-time activities (22 items, $\alpha=0.85$ ).

\section{Construct validity}

Construct validity, the extent to which the measure fits into a network of theoretical relationships, was estimated by correlating the FPI-SF with factors that would be expected to constrain performance. Disease severity was expressed through pulmonary function, specifically $\mathrm{FEV}_{1} \%$ predicted, ${ }^{32}$ and symptoms were measured through the BESC. The FPI-SF was also correlated with BNSI under the premise that basic needs motivate performance and performance fulfills basic needs. Cantril's Ladder hypothesizes that performance is related to life satisfaction.

\section{BESC}

The 89-item BESC evaluates 11 dimensions of the breathlessness experience: dyspnea, fatigue, sleep difficulties, congestion, irritability, anxiety, decathexis, helplessness/ hopelessness, poor memory, peripheral/sensor complaints, and alienation. ${ }^{32-34} \mathrm{~A}$ total score summarizes the overall symptom experience. In the present study, internal consistency reliability estimate for the total score was 0.97 .

\section{BNSI}

The 27-item BNSI asks subjects to rate, on a scale of 1 (terrible) to 7 (delighted), how they feel about various aspects of their lives. Five subscales correspond to Maslow's need categories: physical, safety-security, love belongingness, esteem-self-esteem, and self-actualization. The total score indicates overall perception of need satisfaction. The instrument has been tested for reliability and validity in healthy older adults and patients with COPD. ${ }^{35}$ The internal consistency of the total scale in the present study was 0.95 .

\section{Cantril's Self-anchoring Ladder of Life Satisfaction}

Cantril's Ladder asks subjects to describe their satisfaction with life at the present time, 1 year ago, and 1 year from now on a 10-rung ladder, with the bottom (0) representing the worst possible life and the top (10) the best possible life. ${ }^{36}$ It has been used successfully in studies of the elderly and patients with affective disorders and in evaluating quality of life following cerebral bypass surgery, bone marrow transplant, and renal dialysis. ${ }^{37}$ Satisfaction with life at the present time was used in this study.

\section{Known-groups validity}

Finally, the FPI-SF was subjected to two tests of known-groups validity. The first test compared patients who perceived their 
disease and activity limitation to be mild to moderate with those who perceived their disease and activity limitation to be severe to very severe, anticipating that these patients should score differently on the FPI-SF. The second test compared patients with an $\mathrm{FEV}_{1} \%$ predicted $\geq 50 \%$ (mild to moderate) with those $<50 \%$ (severe to very severe), using the Global Initiative for Chronic Obstructive Lung Disease spirometric classification of COPD severity. ${ }^{38}$

\section{Perceived severity and activity limitation}

FPI-SF subscale and total scale scores of patients who felt their disease and activity limitations were mild to moderate (responded 1 or 2 on a 4-point severity scale and 1 to 3 on a 5 -point activity scale; $n=60$ ) were compared with those who felt these factors were severe to very severe (responded 3 or 4 on the severity scale and 4 or 5 on activity; $n=73$ ).

\section{Analyses}

Cronbach's formula for coefficient alpha $(\alpha)$ was used to estimate the internal consistency reliability of the FPI-SF subscales and total scale. ${ }^{39}$ Reproducibility was estimated using ICC that controls for systematic bias by combining a measure of correlation with a test of the difference between means. For descriptive purposes, Pearson correlation coefficients $(r)$ and mean differences between observations ( \pm standard error) were also calculated.

Pearson product-moment correlations were used to examine the relationship between the FPI and FPI-SF scores; between the FPI-SF and FSQ, DASI, and KAS-R scores; and between the FPI-SF and indicators of disease severity, symptoms, and life satisfaction. Known-groups validity was tested using the independent samples $t$-test procedure to compute Student's $t$-statistics for equal or unequal variance based upon results of the Levene's test. All tests were two-tailed, and the a priori significance level was set at 0.05 . Because this study involved evaluative psychometric analyses, no adjustments were made for multiple tests.

\section{Results}

\section{Sample}

As described in an earlier article, ${ }^{3} 154$ patients participated in the survey; 54 participated in the 2-week reproducibility evaluation. The mean age of the sample was 64.6 years $(\mathrm{SD}=11.4)$. Most were women $(\mathrm{n}=95,62 \%)$ and $11.7 \%$ $(n=18)$ were African-American. The majority were married and living with their spouses $(\mathrm{n}=86,56 \%)$ or widowed $(\mathrm{n}=36,23 \%)$. Twenty percent of the sample $(\mathrm{n}=30)$ lived alone. One-third $(n=50)$ had less than a high school education, $25 \%(\mathrm{n}=38)$ had completed high school, and $25 \%(\mathrm{n}=39)$ had a college education. For patients for whom pulmonary function data were available $(\mathrm{n}=136)$, mean $\mathrm{FEV}_{1}$ was $1.08(\mathrm{SD}=0.51)$ and $\mathrm{FEV}_{1} \%$ predicted was $42.3 \%(\mathrm{SD}=18.5)$. The forced expiratory volume in $1 \mathrm{sec}$ to forced vital capacity ratio $\left(\mathrm{FEV}_{1} / \mathrm{FVC}\right)$ was 0.51 $(\mathrm{SD}=0.15)$.

The 40 family members were primarily spouses (90\%) (others included housemates and adult children), and 51\% were men. Mean age of the group was 61.6 years $(\mathrm{SD}=8.9$ years). Over half (64\%) had a high school education or above, and 36\% were employed full-time. Respondents had resided in the same household for an average of 29.1 years $( \pm 14.4)$, and most (85\%) received no help around the home or with their significant other's care.

\section{Expert review}

The CVI for the FPI-SF was $100 \%$. Of the seven experts, six rated all of the 32 items relevant or very relevant ( 3 or 4 ).

\section{Reliability}

Internal consistency and test-retest reliability estimates for the six subscales and total scale of the FPI-SF are provided in Table 2. Subscale internal consistency levels ranged from 0.76 (physical exercise) to 0.89 (household maintenance), with a total scale $\alpha$ of 0.93 . ICCs ranged from 0.68 (physical

Table 2 Internal consistency and test-retest reliability estimates for the FPI-SF

\begin{tabular}{|c|c|c|c|c|c|}
\hline \multirow[t]{2}{*}{ Dimension } & \multirow[t]{2}{*}{ No. of items (k) } & \multirow[t]{2}{*}{ Cronbach's $\alpha^{\prime}$} & \multicolumn{3}{|c|}{ Test-retest reliability } \\
\hline & & & Pearson (r) & Intraclass (ICC) & $\begin{array}{l}\text { Mean } \\
\text { difference (SE) }\end{array}$ \\
\hline Body care & 5 & 0.82 & $0.77^{2}$ & $0.76^{2}$ & $0.11(0.05)$ \\
\hline Household maintenance & 8 & 0.89 & $0.86^{2}$ & $0.85^{2}$ & $0.31(0.05)$ \\
\hline Physical exercise & 5 & 0.76 & $0.69^{3}$ & $0.68^{3}$ & $0.15(0.07)$ \\
\hline Recreation & 5 & 0.81 & $0.8 \mathrm{I}^{4}$ & $0.80^{4}$ & $-0.02(0.07)$ \\
\hline Spiritual activities & 4 & 0.82 & $0.75^{5}$ & $0.75^{5}$ & $-0.16(0.11)$ \\
\hline Social activities & 5 & 0.81 & $0.76^{3}$ & $0.76^{3}$ & $0.12(0.08)$ \\
\hline FPI-SF total score & 32 & 0.93 & $0.88^{5}$ & $0.88^{5}$ & $0.03(0.04)$ \\
\hline
\end{tabular}

Notes: ' $n=105$ (total) - 150 (body care) with variation due to missing data; ${ }^{2} n=54 ;{ }^{3} n=53 ;{ }^{4} n=52 ;{ }^{5} n=50$. 
Table 3 Pearson correlation coefficients between the FPI-SF and concurrent validity measures

\begin{tabular}{|c|c|c|c|c|c|}
\hline \multirow[t]{3}{*}{ Dimension } & \multicolumn{5}{|c|}{ Concurrent validity } \\
\hline & \multicolumn{3}{|c|}{ Jette's FSQ $(n=|40-| 53)$} & \multicolumn{2}{|c|}{ KAS-R (n = 35-39) } \\
\hline & ADL & IADL & DASI & $\begin{array}{l}\text { Socially } \\
\text { expected } \\
\text { activities }\end{array}$ & $\begin{array}{l}\text { Free-time } \\
\text { activities }\end{array}$ \\
\hline Body care & $0.67 * * *$ & $0.67 * * *$ & $0.51 * * *$ & $0.42 * *$ & $-0.40^{*}$ \\
\hline Household maintenance & $0.59 * * *$ & $0.72^{* * *}$ & $0.62 * * *$ & $0.46 * *$ & $-0.37^{*}$ \\
\hline Physical exercise & $0.52^{* * *}$ & $0.69 * * *$ & $0.64 * * *$ & 0.24 & -0.29 \\
\hline Recreation & $0.59 * * *$ & $0.58 * * *$ & $0.59 * * *$ & $0.55 * * *$ & $-0.53 * *$ \\
\hline Spiritual activities & $0.24 * *$ & 0.14 & $0.16 *$ & 0.20 & -0.26 \\
\hline Social activities & $0.53 * * *$ & $0.55 * * *$ & $0.51 * * *$ & 0.44 & $-0.37^{*}$ \\
\hline FPI-SF total score & $0.7 I^{* * * *}$ & $0.73 * * *$ & $0.65 * * *$ & 0.51 & $-0.49 * *$ \\
\hline
\end{tabular}

Notes: $* P<0.05 ; * * P<0.01$; $* * * P<0.001$.

exercise) to 0.85 (household maintenance), with a total scale ICC of 0.88 .

\section{Validity}

Correlations between the FPI and FPI-SF total scores were very high (0.98). Subscale correlations between the six subscales were as follows: body care: 0.97 , household maintenance: 0.93 , physical exercise: 0.97 , recreation: 0.93 , spiritual activities: 0.98 , and social activities: 0.95 .

Pearson correlation coefficients between the measures of concurrent validity and the FPI-SF subscales and total scale score are provided in Table 3. All of the coefficients were within 0.11 of the long form, with $60 \%$ within 0.04 . All but one of the correlations with the FSQ and DASI were statistically significant. Ten of the 14 relationships with the KAS-R were statistically significant. The FPI-SF total score correlated significantly with each of the concurrent validation measures.

Correlation coefficients between the four measures of construct validity and the FPI-SF subscale and total scales

Table 4 Pearson correlation coefficients between the FPI-SF and construct validity measures

\begin{tabular}{lllll}
\hline Dimension & \multicolumn{4}{l}{ Construct validity measure } \\
\cline { 2 - 5 } & $\begin{array}{l}\text { FEV,\% } \\
\text { predicted }\end{array}$ & BESC & BNSI & $\begin{array}{l}\text { Cantril's } \\
\text { Ladder }\end{array}$ \\
\hline Body care & $0.32^{* *}$ & $-0.5 I^{* *}$ & $0.46 * *$ & $0.56 * *$ \\
Household maintenance & $0.43^{* *}$ & $-0.4 I^{* *}$ & $0.26 *$ & $0.42^{* *}$ \\
Physical exercise & $0.37^{* *}$ & $-0.49 * *$ & $0.44^{* *}$ & $0.50^{* *}$ \\
Recreation & $0.29 *$ & $-0.50^{* *}$ & $0.55^{* *}$ & $0.54 * *$ \\
Spiritual activities & 0.10 & $-0.32^{* *}$ & $0.4 I^{* *}$ & $0.29 * *$ \\
Social activities & $0.30^{* *}$ & $-0.5 I^{* *}$ & $0.50^{* *}$ & $0.54 * *$ \\
FPI-SF total score & $0.36 * *$ & $-0.6 I^{* *}$ & $0.6 I^{* *}$ & $0.63 * *$ \\
\hline Notes: $* P<0.01 ; * P<0.001$. & & &
\end{tabular}

Notes: $* p<0.01$; $* p<0.001$. are provided in Table 4 . All of the coefficients were within 0.15 of the long form, with $71 \%$ within 0.04 . The spiritual activities subscale did not correlate with $\mathrm{FEV}_{1} \%$ predicted, a characteristic shared by the long form. All of the correlations between FPI-SF total score and the construct validation measures were statistically significant and were higher than for the long form for two of the four variables.

Evidence of known-groups validity of the FPI-SF is shown in Table 5. Patients who perceived their disease and activity limitation as severe to very severe had significantly lower scores on the FPI-SF total and all six of the subscales as compared with those who perceived their disease and activity limitation as mild to moderate. The FPI-SF total and five of the six subscales also discriminated between patients with an $\mathrm{FEV}_{1}$ less than and greater than $50 \%$ predicted. Once again these results were identical to those reported for the long form. ${ }^{3}$

\section{Discussion}

The FPI was designed to quantify patient-reported functional performance in COPD. The original measure was based on an explicit analytical framework, existing literature, and the experiences of the patients themselves, with evaluative input from clinical and scientific experts. ${ }^{3}$ The purpose of this study was to create a shorter version of the FPI while preserving the integrity and psychometric properties of the original instrument. To optimize content validity, the item reduction process was informed by qualitative data from the original development process as well as item-level quantitative evaluation.

Reliability estimates suggest the FPI-SF is internally consistent and stable over time with values similar to the 
Table 5 FPI-SF subscale and total scale scores by perceived disease severity and activity limitation and by disease severity (FEV,\% predicted)

\begin{tabular}{|c|c|c|c|c|c|c|}
\hline \multirow[t]{2}{*}{ Dimension } & \multicolumn{3}{|c|}{ Perceived disease severity and activity limitation } & \multicolumn{3}{|c|}{ FEV $\%$ predicted } \\
\hline & $\begin{array}{l}\text { Mild to } \\
\text { moderate } \\
(n=60)\end{array}$ & $\begin{array}{l}\text { Severe to very } \\
\text { severe } \\
(n=73)\end{array}$ & t-Statistic & $\begin{array}{l}\geq 50 \% \\
(n=44)\end{array}$ & $\begin{array}{l}<50 \% \\
(n=92)\end{array}$ & $t$-Statistic \\
\hline Body care & $2.80(0.29)$ & $2.16(0.61)$ & $7.36 *$ & $2.73(0.38)$ & $2.37(0.58)$ & $4.3 I^{1 *}$ \\
\hline Household maintenance & $1.87(0.52)$ & $0.92(0.69)$ & $9.15^{*}$ & $1.76(0.66)$ & $1.22(0.74)$ & $4.09 *$ \\
\hline Physical exercise & $\mathrm{I} .57(0.59)$ & $0.83(0.56)$ & $7.26^{*}$ & $1.58(0.67)$ & $1.02(0.63)$ & $4.66 *$ \\
\hline Recreation & $2.49(0.57)$ & $1.53(0.78)$ & $7.81^{*}$ & $2.38(0.62)$ & $1.87(0.87)$ & $3.81^{1 *}$ \\
\hline Spiritual activities & $1.85(1.11)$ & 1.15 (1.03) & $3.62 *$ & $1.66(1.13)$ & $1.37(1.14)$ & 1.38 \\
\hline Social activities & $2.06(0.74)$ & I.I 5 (0.77) & $6.88 *$ & $2.06(0.88)$ & $1.43(0.80)$ & $4.05^{*}$ \\
\hline FPI-SF total score & $2.11(0.42)$ & $1.29(0.50)$ & $9.91 *$ & $2.03(0.53)$ & $1.56(0.60)$ & $4.26 *$ \\
\hline
\end{tabular}

Notes: ' $t$-Test for unequal variance. $* P \leq 0.001$.

longer form. Internal consistency levels for five of the six subscales exceeded Nunnally's criterion of 0.80 for basic research, with the total scale score exceeding the recommended 0.90 for applied settings and approaching the 0.95 recommended for applied research. ${ }^{39}$ The FPI-SF was used in studies by Wall ${ }^{40}$ and Yeh et al, ${ }^{9}$ who found similar internal consistency levels $(0.94 ; n=119$ and $0.93 ; n=138$, respectively).

The two versions of the instrument were highly correlated, with $96 \%$ common variance in the total scores and $87 \%-96 \%$ shared variance in subscale scores. Concurrent validity of the short form was consistent with that of the original long form. Significant correlations were found between the FPISF and the DASI, FSQ, and relatives' perception of patient performance, with magnitudes like the original. The construct validity of the FPI-SF was also supported. Once again consistent with the long form, the relationship between this measure and indicators of basic needs (BNSI), life satisfaction (Cantril's Ladder), and symptoms (BESC) were statistically significant with moderate to large effect sizes. Correlations between $\mathrm{FEV}_{1} \%$ predicted and the FPI-SF subscales and total scale were consistent with those observed with the long form, with values within 0.07 , with all but one of the scales within 0.03 . Wall used the short form in a study of 97 patients with moderate to severe COPD and found significant relationships between the FPI-SF and dyspnea $(r=0.62, P<0.01)$ and self-efficacy $(r=0.58, P<0.01) .^{40}$

Like its longer counterpart, the FPI-SF was able to distinguish patient groups based on perceived severity and activity limitation as well as pulmonary function. The FPI-SF's sensitivity to treatment effects was shown in a randomized, controlled pilot study examining the effect of yoga on dyspnea-related distress and functional performance in patients with COPD, where significant improvements were seen in FPI-SF score $(\mathrm{ES}=0.79$, $P=0.04)$ in the yoga-trained group compared with usual care controls. ${ }^{41}$

Evidence of concurrent and construct validity continued to be weakest for the spiritual activities subscale, with significant but relatively weak correlation coefficients. Because patients reported in qualitative interviews that they felt spiritual activities were an important part of their daily performance, the authors felt this subscale should be represented in the short-form version of the FPI. Further qualitative study of spiritual activity as a domain of functional performance for patients with COPD and additional consideration as to the optimal measurement methods for this aspect of performance may be warranted.

\section{Conclusion}

The FPI-SF appears to be a viable alternative for those seeking a shorter and more parsimonious measure of functional performance. This study used the original validation data to test the performance properties of the short form relative to its longer counterpart. Results provided evidence of internal consistency reliability, reproducibility, and concurrent, construct, and known-groups validity. Further examination of the instrument's performance properties in new samples is warranted.

\section{Acknowledgments}

This work was supported by the Division of Intramural Research, National Institute of Nursing Research, National Institutes of Health (NIH), Protocol \#Z01 NR00008-01 HRHI, Isolating Functional Performance in Chronic Illness. Data for this study were gathered while Dr Leidy 
was an NIH intramural fellow. Analyses were performed while Dr Knebel was an employee and Dr Leidy was a guest researcher at NIH. The views expressed are those of the authors and not necessarily those of the National Institute of Nursing Research, the National Institutes of Health, or the Department of Health and Human Services. The authors thank Dr Robert Wise, Dr Cynthia Rand, and Victoria Heineman of the Johns Hopkins University Asthma and Allergy Center and Kathy Fedenko of the US Food and Drug Administration, formerly a research nurse specialist at the NINR, for their assistance during data collection.

\section{Disclosure}

The authors report no conflicts of interest in this work.

\section{References}

1. Leidy NK. Functional status and the forward progress of merrygo-rounds: toward a coherent analytical framework. Nurs Res. 1994; 43(4):196-202.

2. Leidy NK. Using functional status to assess treatment outcomes. Chest. 1994;106(6):1645-1646.

3. Leidy NK. Psychometric properties of the functional performance inventory in patients with chronic obstructive pulmonary disease. Nurs Res. 1999;48(1):20-28.

4. Leidy NK, Haase JE. Functional performance in people with chronic obstructive pulmonary disease: a qualitative analysis. ANSAdv Nurs Sci. 1996;18(3):77-89.

5. Lynn MR. Determination and quantification of content validity. Nurs Res. 1986;35(6):382-385.

6. Waltz CF, Bausell RB. Nursing Research: Design, Statistics, and Computer Analysis. Philadelphia (PA): F.A. Davis; 1981.

7. Williams V, Bruton A, Ellis-Hill C, McPherson K. What really matters to patients living with chronic obstructive pulmonary disease? An exploratory study. Chron Respir Dis. 2007;4(2):77-85.

8. Aberg AC, Sidenvall B, Hepworth M, O'Reilly K, Lithell H. On loss of activity and independence, adaptation improves life satisfaction in old age-a qualitative study of patients' perceptions. Qual Life Res. 2005; 14(4):1111-1125.

9. Yeh ML, Chen HH, Liao YC, Liao WY. Testing the functional status model in patients with chronic obstructive pulmonary disease. $J$ Adv Nurs. 2004;48(4):342-350.

10. Ozkan S, Gemicioglu B, Durna Z, Demir T. Turkish version of the functional performance inventory used on patients with chronic obstructive pulmonary disease. Saudi Med J. 2009;30(8): 1098-1100.

11. Stull DE, Leidy NK, Jones PW, Stahl E. Measuring functional performance in patients with COPD: a discussion of patient-reported outcome measures. Curr Med Res Opin. 2007;23(11):2655-2665.

12. Larson JL, Kapella MC, Wirtz S, Covey MK, Berry J. Reliability and validity of the functional performance inventory in patients with moderate to severe chronic obstructive pulmonary disease. J Nurs Meas. 1998;6(1):55-73.

13. Leidy NK, Knebel A. Clinical validation of the Functional Performance Inventory in patients with COPD. Respir Care. 1999;44(8): 932-939.

14. Reishtein JL. Relationship between symptoms and functional performance in COPD. Res Nurs Health. 2005;28(1):39-47.

15. Kapella MC, Larson JL, Patel MK, Covey MK, Berry JK. Subjective fatigue, influencing variables, and consequences in chronic obstructive pulmonary disease. Nurs Res. 2006;55(1):10-17.
16. Jette AM, Davies AR, Cleary PD, et al. The Functional Status Questionnaire: reliability and validity when used in primary care. J Gen Intern Med. 1986;1(3):143-149.

17. Yarnold PR, Bryant FB, Repasy AB, Martin GJ. The factor structure and cross-sectional distributional properties of the Beth Israel/ UCLA Functional Status Questionnaire. J Behav Med. 1991;14(2): $141-153$.

18. Allen JK, Becker DM, Swank RT. Factors related to functional status after coronary artery bypass surgery. Heart Lung. 1990;19(4): 337-343.

19. Barsky AJ, Cleary PD, Klerman GL. Determinants of perceived health status of medical outpatients. Soc Sci Med. 1992;34(10): 1147-1154.

20. Einarsson G, Grimby G. Disability and handicap in late poliomyelitis. Scand J Rehabil Med. 1990;22(2):113-121.

21. Jette AM, Cleary PD. Functional disability assessment. Phys Ther. 1987;67(12):1854-1859.

22. Katz JN, Larson MG, Phillips CB, Fossel AH, Liang MH. Comparative measurement sensitivity of short and longer health status instruments. Med Care. 1992;30(10):917-925.

23. Reuben DB, Rubenstein LV, Hirsch SH, Hays RD. Value of functional status as a predictor of mortality: results of a prospective study. Am J Med. 1992;93(6):663-669.

24. Rubenstein LV, Calkins DR, Young RT, et al. Improving patient function: a randomized trial of functional disability screening. Ann Intern Med. 1989;111(10):836-842.

25. Tedesco C, Manning S, Lindsay R, Alexander C, Owen R, Smucker ML. Functional assessment of elderly patients after percutaneous aortic balloon valvuloplasty: New York Heart Association classification versus functional status questionnaire. Heart Lung. 1990;19(2): 118-125.

26. Hlatky MA, Boineau RE, Higginbotham MB, et al. A brief selfadministered questionnaire to determine functional capacity (the Duke Activity Status Index). Am J Cardiol. 1989;64(10):651-654.

27. Hogarty GE, Katz MM. Norms of adjustment and social behavior. Arch Gen Psychiatry. 1971;25(5):470-480.

28. Katz M, Lyerly S. Methods of measuring adjustment and social behavior in the community. I. Rationale, description, discriminative validity, and scale development. Psych Rep. 1963;13: 503-535.

29. Leidy NK, Traver GA. Adjustment and social behaviour in older adults with chronic obstructive pulmonary disease: the family's perspective. J Adv Nurs. 1996;23(2):252-259.

30. McSweeny AJ, Grant I, Heaton RK, Prigatano GP, Adams KM. Relationship of neuropsychological status to everyday functioning in healthy and chronically ill persons. J Clin Exp Neuropsychol. 1985;7(3): 281-291.

31. Prigatano GP, Wright EC, Levin D. Quality of life and its predictors in patients with mild hypoxemia and chronic obstructive pulmonary disease. Arch Intern Med. 1984;144(8):1613-1619.

32. Lung function testing: selection of reference values and interpretative strategies. American Thoracic Society. Am Rev Respir Dis. 1991;144(5): 1202-1218.

33. Kinsman RA, Fernandez E, Schocket M, Dirks JF, Covino NA. Multidimensional analysis of the symptoms of chronic bronchitis and emphysema. J Behav Med. 1983;6(4):339-357.

34. Kinsman RA, Yaroush RA, Fernandez E, Dirks JF, Schocket M, Fukuhara J. Symptoms and experiences in chronic bronchitis and emphysema. Chest. 1983;83(5):755-761.

35. Leidy NK. Operationalizing Maslow's theory: development and testing of the basic need satisfaction inventory. Issues Ment Health Nurs. 1994; 15(3):277-295.

36. Cantril H. The Patterns of Human Concerns. New Brunswick (NJ): Rutgers University Press; 1965.

37. Thomas LE, Chambers KO. Phenomenology of life satisfaction among elderly men: quantitative and qualitative views. Psychol Aging. 1989; 4(3):284-289. 
38. Global Initiative for Chronic Obstructive Lung Disease (GOLD) Executive Summary: Global Strategy for the Diagnosis, Management, and Prevention of Chronic Obstructive Pulmonary Disease. Medical Communications Resources, Inc.; 2009. Available from: http://www. goldcopd.com/. Accessed Aug 2010.

39. Nunnally JC, Bernstein I. Psychometric Theory. 3rd ed. New York: McGraw-Hill; 1994.
40. Wall MP. Predictors of functional performance in community-dwelling people with COPD. J Nurs Scholarsh. 2007;39(3):222-228.

41. Donesky-Cuenco D, Nguyen HQ, Paul S, Carrieri-Kohlman V. Yoga therapy decreases dyspnea-related distress and improves functional performance in people with chronic obstructive pulmonary disease: a pilot study. J Altern Complement Med. 2009;15(3):225-234.

International Journal of COPD

\section{Publish your work in this journal}

The International Journal of COPD is an international, peer-reviewed journal of therapeutics and pharmacology focusing on concise rapid reporting of clinical studies and reviews in COPD. Special focus is given to the pathophysiological processes underlying the disease, intervention programs, patient focused education, and self management protocols.

\section{Dovepress}

This journal is indexed on PubMed Central, MedLine and CAS. The manuscript management system is completely online and includes a very quick and fair peer-review system, which is all easy to use. Visit $\mathrm{http}: / /$ www.dovepress.com/testimonials.php to read real quotes from published authors.

Submit your manuscript here: http://www.dovepress.com/international-journal-of-copd-journal 